\title{
Impact of Electric Vehicles on a Carbon Constrained Power System-A Post 2020 Case Study
}

\author{
Zhebin Sun', Kang Li ${ }^{1}$, Zhile Yang ${ }^{1}$, Qun Niư ${ }^{2}$, Aoife Foley ${ }^{3}$ \\ ${ }^{1}$ School of Electronics, Electrical Engineering and Computer Science, Queen's University Belfast, Belfast BT9 \\ $5 \mathrm{AH}, \mathrm{UK}$ \\ ${ }^{2}$ School of Mechatronic Engineering and Automation, Shanghai Key Laboratory of Power Station Automation \\ Technology, Shanghai University, Shanghai 200072, China \\ ${ }^{3}$ School of Mechanical and Aerospace Engineering, Queen's University Belfast, Belfast BT9 5AH, UK \\ Email: zsun03@qub.ac.uk, k.li@qub.ac.uk, zyang07@qub.ac.uk
}

Received January 2015

\section{Abstract}

Electric vehicles (EVs) offer great potential to move from fossil fuel dependency in transport once some of the technical barriers related to battery reliability and grid integration are resolved. The European Union has set a target to achieve a 10\% reduction in greenhouse gas emissions by 2020 relative to 2005 levels. This target is binding in all the European Union member states. If electric vehicle issues are overcome then the challenge is to use as much renewable energy as possible to achieve this target. In this paper, the impacts of electric vehicle charged in the all-Ireland single wholesale electricity market after the 2020 deadline passes is investigated using a power system dispatch model. For the purpose of this work it is assumed that a $10 \%$ electric vehicle target in the Republic of Ireland is not achieved, but instead 8\% is reached by 2025 considering the slow market uptake of electric vehicles. Our experimental study shows that the increasing penetration of EVs could contribute to approach the target of the EU and Ireland government on emissions reduction, regardless of different charging scenarios. Furthermore, among various charging scenarios, the off-peak charging is the best approach, contributing $2.07 \%$ to the target of $10 \%$ reduction of Greenhouse gas emissions by 2025.

\section{Keywords}

Carbon Emissions, Electric Vehicles, Power System, PLEXOS, Energy Forecasting

\section{Introduction}

In recent years, climate changes caused by carbon emissions have attracted considerable attention worldwide [1]. "WMO greenhouse gases bulletin” published by World Meteorological Organization in 2011 pointed out that the concentration of greenhouse gases (GHG) in the atmosphere has reached a high record in 2010. The average 
concentration of $\mathrm{CO}_{2}$ reached $389.0 \mathrm{ppm}$, while the Nitrous oxide reached $323.2 \mathrm{ppb}$, with the increase of $39 \%$ and $20 \%$ respectively comparing with their counterparts during the industrial revolution [2]. The increased GHG emissions are largely due to the use of fossil fuels. The atmospheric pollution produced by transportation industry due to large usage of fossil fuel, oil and natural gas, has become a major issue, surpassing the traditional industrial pollution [3]. In terms of carbon emissions, transportation and electricity industry are the two key sectors [4]. In the European Union (EU) there are strict binding GHG reductions targets and renewable energy targets called 20 - 20 by 2020 [5]. In each EU member state the targets have been implemented. For example in the Republic of Ireland it is proposed that GHG emissions need to be cut by $60 \%$ - 80\% by 2050 [6]. Carbon dioxide $\left(\mathrm{CO}_{2}\right)$ emission is a major part of GHG which accounted for 80\% of all GHG emissions in 1990-2010. Thus the Irish government has set a target that $\mathrm{CO}_{2}$ emissions be reduced to $20 \%$ by 2020 in keeping with EU directives [7]. Transport is one of the main sectors dependent on fossil fuels, and is thus a major source of GHG emissions. It is believed that electric vehicles (EV) can reduce heavy fossil fuel dependency, support better renewable power integration and thus reduce GHG emissions. In the Republic of Ireland, a country with a large wind power resource the Irish government set a 10\% EV target by 2020 [8]. Consequently, it is thought that a better reduction in GHG emissionsis achievable and increased security of energy supply by reducing oil imports and more efficient wind power integration may be possible. However, there are many technical challenges relating to mass EV deployment, such as battery reliability, as well as the impacts of stochastic charging and potentially discharging on both the grid and the generators.

A number of studies have examined the interaction of EVs with the power system considering emissions. For example, the $\mathrm{CO}_{2}$ emissions of battery electric vehicles (BEV) and plug-in hybrid electric vehicles (PHEV) are compared in [9] [10] provides a bottom-up model of EV carbon emissions and energy impacts in the Republic of Ireland.

In this paper, the EV technologies are briefly reviewed and the impacts of EV charged in the all-Ireland single wholesale electricity market after the 2020 deadline passes is investigated using a power system dispatch model called PLEXOS for power systems. For the purpose of this work it is assumed that a $10 \%$ electric vehicle target in the Republic of Ireland is not achieved, but instead 8\% is reached by 2025 considering the slower market uptake of electric vehicles. The test system is the single wholesale electricity market (SEM) of Northern Ireland and the Republic of Ireland in 2025. Four different EV charging scenarios are analysed to determine increased renewable energy penetration, the net reduction in $\mathrm{CO}_{2}$ emissions and the percentage contribution to the 2020 target.

\section{Overview of EV Technology}

\subsection{Electric Vehicle Types}

There are several types of EVs. The common types are BEVs and PHEVs. The BEV is powered by $100 \%$ electric energy, whereas PHEVs are powered by electric energy, as well as a downsized combustion engines. Both types have an electric motor powered by a rechargeable battery. This battery is recharged by connecting it to a power supply. A BEV does not emit any tail-pipe emissions because it operates in only electric mode. However, a PHEV produces emissions when using their combustion engines to drive the car. Nevertheless, both types may implicitly produce GHG emissions due to the need to charge the battery from the grid where thermal generation units are in use.

\subsection{Electric Vehicle Battery Charging}

The preferred battery type for the majority of EV manufacturers is lithium-ion due to that it has a high storage capacity. The current average battery driving range and battery capacity of commercial BEVs in the market are $130 \mathrm{~km}$ and $22 \mathrm{kWh}$ respectively [11]. Battery performance of EVs and their ability to achieve stated driving ranges is highly dependable on the driving styles and environment conditions.

There are three types of charging options available for EVs, including home charging, public charging and fast charging. Table 1 shows the charging options [11].

\section{Model of the SEM and EV Charging Scenarios}

In order to assess the impact of different EV charging scenarios on the power system, a base line power system 
Table 1. Battery charging options.

\begin{tabular}{ccc}
\hline Type & Electrical & Resulting Charge \\
\hline Home Charging & $230 \mathrm{~V} 16 \mathrm{~A}$ & $100 \%$ in $6-8$ hours \\
Public Charging & $400 \mathrm{~V} 32 \mathrm{~A}$ & $50 \%$ in 30 mins \\
Fast Charging & $400 \mathrm{~V}$ 63A & $80 \%$ in 30 mins \\
\hline
\end{tabular}

model is first built. PLEXOS is an MIP-based (mixed integer programming algorithm) software used for the next-generation energy market simulation and optimization [12]. The software can realistically replicate the actual operation of generators in the physical market as all technical constraints can be modeled and obeyed. PLEXOS can be used to minimize cost or maximize profit and to integrate the analysis of variable energy resources. It could also be used for electrical market analysis.

\subsection{SEM Test System}

The Republic of Ireland and Northern Ireland share a synchronous power system known as the All-Island Gird (AIG), which facilitates the operation of the SEM. The SEM system was built in PLEXOS using [13]. These are based on published data from NERA Economic Consultants (2008), KEMA (2007) and Energy Regulation (2011) [14]. GDP grossing function from Gross Domestic Product Preliminary Estimate 2014 association with the growth of economy potential output and population growth curve were used to update 2007-2008 energy load demand of Ireland for the year of 2025 [15]. Using gross domestic product predictions for Ireland and the UK then load demand in each hour in a typical day by 2025 was extrapolated [16]. The totally load demand in 2025 as predicted to be $57,325 \mathrm{GWh}$.

The SEM 2025 baseline model needs a number of generation data and the generation schedule of 2025. In this research the generation data was developed based on the report of SONI 2014 and EirGrid 2014 [17]. We have updated the technical details for all the generators. The total predicted installed capacity for 2025 was estimated to be 14,983 MW. Table 2 shows all the types of generators dispatched in the SEM by 2025 without an EV load. It is obviously that gas, coal and wind generations were the three largest contributors to generation capacity.

It is forecasted that approximately 20,032 MWh are available for dispatch via wind generators and the wind generation data was updated for EirGrid since 2009. It is assumed that the power supplied by wind generation is limited to $70 \%$ of total energy demand.

The fuel price is set and updated for generation on the basis of the fuel market form UK Fuel Price forecast report [18]. The carbon cost is set to $£ 20 / t$ for $\mathrm{CO}_{2}$, which is referenced with the carbon prices usually used in PLEXOS, for instance, the carbon cost was set to £30/t in PRIMES EU-wide energy model. The fuel prices are listed in Table 3.

The SEM is linked to the British Electricity Trading and Transmission Arrangement (BETTA) via the 500 MW Moyle Interconnector. It is assumed that any existing flow constraints on the Moyle Interconnector have been removed by 2025. Another $500 \mathrm{MW}$ interconnector is under construction between Rush, County Dublin to Bark by Beach, North Wales, which is called as the East West Interconnector (EWIC). In the present work, it was assumed that the EWIC commenced operation in 2012. Total interconnection to BETTA in PLEXOS in 2025 is represented as a single gas generator with 12 different heat rates and operating costs using the SEM validated market model produced by CER and UR (2011). This is because gas-fired generation is the predominant marginal plant in the BETTA and there is a strong correlation between the cost of gas-fired generation and the BETTA market price.

\subsection{EV Charging Scenarios}

An EV target has been set up by the Irish government that $10 \%$ of all vehicles fleet in all island should be replaced by EVs by 2025. It is assumed for this analysis that the $10 \% \mathrm{EV}$ target may be difficult to achieve considering some of the existing challenges and slow EV sales. Therefore a figure of $8 \%$ EV market share was assumed in 2025. Thus the total EVs is calculated to be 343,918 vehicles. Furthermore the EV types were limited to just PHEV with a $3.3 \mathrm{~kW}$ and $16 \mathrm{kWh}$ battery in this analysis. Four EV charging profiles were examined, including 1) off-peak and 2) peak charging, 3) Electric Power Research Institute (EPRI) [19] EV charging data 
Table 2. Generation mix for 2025 without EV load.

\begin{tabular}{ccc}
\hline Fuel & Generation $(\mathrm{GWh})$ & Share of Generation (\%) \\
\hline Goal & 6525.69 & 11.59 \\
Distillate Oil & 2.48 & 0.00 \\
Gas & 21797.59 & 37.32 \\
Hydro & 1825.78 & 3.16 \\
Pumped storage & 152.49 & 0.27 \\
Wave & 707.26 & 1.23 \\
Wind & 19979.85 & 34.71 \\
Peat & 2788.59 & 4.84 \\
Interconnectors & 3756.76 & 6.86 \\
\hline
\end{tabular}

Table 3. Fuel prices.

\begin{tabular}{cc}
\hline Fuel type & Cost £/GJ \\
\hline Gas & 7.02 \\
Oil & 12.06 \\
Coal & 2.12 \\
Peat & 3.18 \\
Hydro & 0 \\
\hline
\end{tabular}

and 4) stochastic charging as illustrated in Figure 1 during a one day period.

1) Off-peak and peak charging profiles

Rate of EV domestic charging for PHEVs with a $16 \mathrm{kWh}$ battery is shown in Table 4. Off-Peak charging profile is obtained from this EV data associated with the No. of EV in Ireland using 0.88 efficiency if charging from 00:00. The charging power was calculated as $847.76 \mathrm{MW}$. It is assumed that $85 \%$ of EVs charge during the week and 15\% of EVs charge at the weekend when built the charging profile. Off-Peak charging data are listed in Table 5. This charging profile has been expanded to the whole year of 2025. Then the results were added as a purchaser load in PLEXOS 2025 baseline model. It can be seen that the EV's Peak charging profiles are similar with Off-Peak during the period of charging from 16:00 to 24:00.

2) EPRI Charging Profiles

An aggregated charge profile was created for the fleet of PHEVs in the model. $100 \%$ of the charge energy requirements are apportioned to each hour of the day. The data of EPRI charging are listed in Table 6. In this analysis, it was assumed that the highest charging loads occur during late night and early morning hours whereas the modest loads from daytime. The public or workplace charging presumably occurred in the middle of the day. Hours of minimal charging correspond roughly with commute times. This specific charge profile creates a scenario where $74 \%$ of the charging energy is delivered from 10:00 p.m. to 6:00 a.m. (nominally off-peak). The remaining $26 \%$ is provided between 6:00 a.m. to 10:00 p.m. It is one of the simplest scenarios among many possible scenarios and it represents an initial approximation of aggregate charging behavior in a fleet of PHEVs. The charging power was calculated as 467.73 MW.

3) Stochastic charging profiles

The stochastic charging profile is very similar to the EPRI charging profile, but it has a random percent value for each hour. Both of EPRI and stochastic charging profiles' function are number of all EVs multiplying 16 kWh for each PHEV capacity, and then multiplying the percent of each hour.

\subsection{SEM Baseline Model}

The power generation for the regular load demand in the SEM in 2025 is met by wind, gas and coal. As shown in Table 2 that 34.71\% of power comes from wind, 37.32\% power from gas and 11.59\% from coal. So the base 


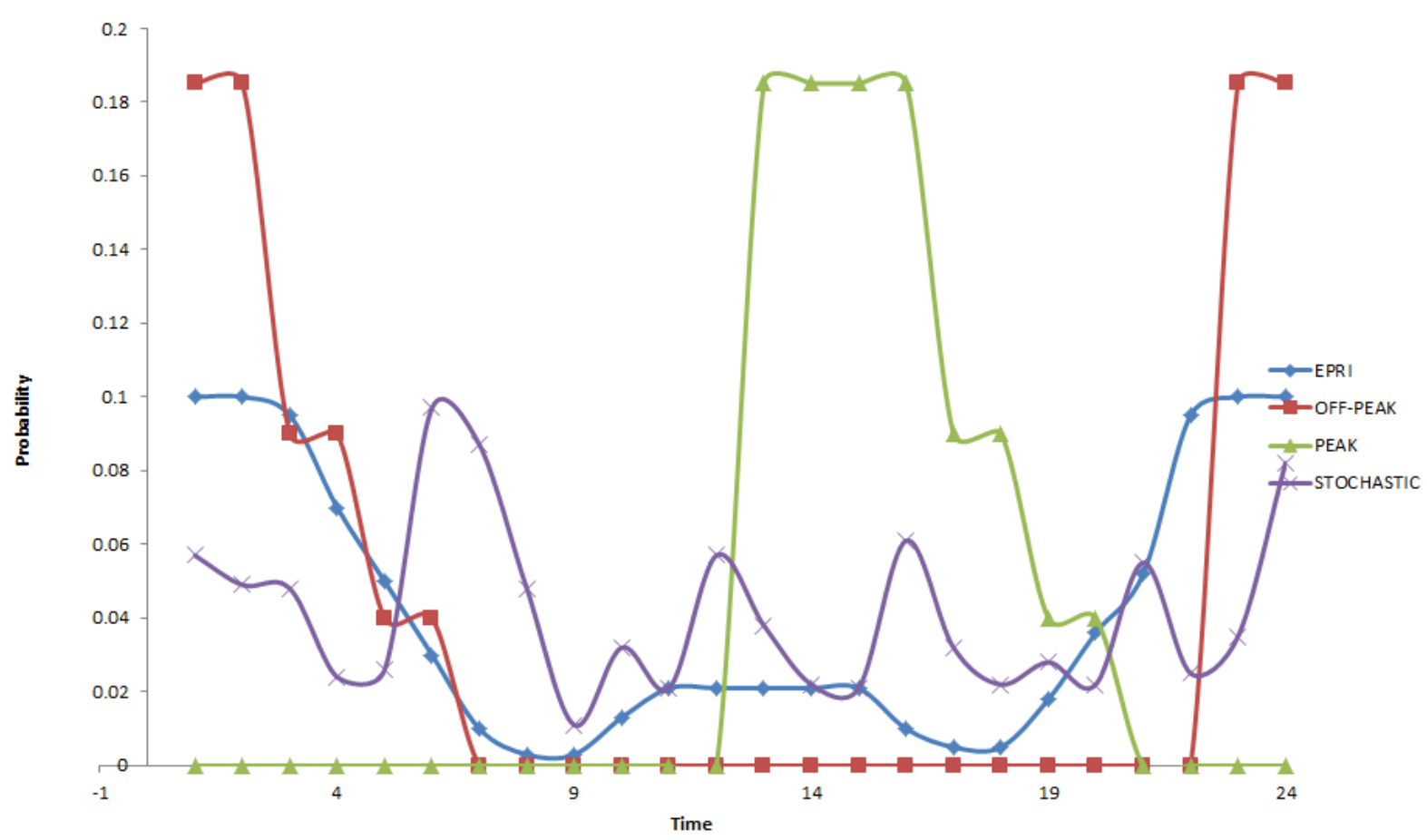

Figure 1. All type of EV charging profiles.

Table 4. Rate of EV domestic charging for PHEVs with 16 kWh battery.

\begin{tabular}{ccc}
\hline Period & State of Charge & Charge Rate $(\mathrm{kWh})$ \\
\hline First 4 hours & $73 \%$ & 2.9 \\
Intermediate 2 hours & $90 \%$ & 1.45 \\
Final 2 hours & $100 \%$ & 0.58 \\
\hline
\end{tabular}

Table 5. Off-Peak charging data for PHEV load demand.

\begin{tabular}{rcccc}
\hline Time of Charge & $00: 00$ & $01: 00$ & $02: 00$ & $03: 00$ \\
Weekday Load & 847.7 & 847.7 & 847.7 & 847.7 \\
Weekend Load & 149.6 & 149.6 & 149.6 & 149.6 \\
Time of Charge & $04: 00$ & $05: 00$ & $06: 00$ & $07: 00$ \\
Weekend Load & 423.8 & 423.8 & 169.5 & 169.5 \\
Weekend Load & 74.8 & 74.8 & 29.9 & 29.9 \\
\hline
\end{tabular}

Table 6. Data of EPRI charging.

\begin{tabular}{ccccccc}
\hline Time & $01: 00$ & $02: 00$ & $03: 00$ & $04: 00$ & $05: 00$ & $06: 00$ \\
Charge percent & $10 \%$ & $10 \%$ & $9 \%$ & $6 \%$ & $4 \%$ & $2 \%$ \\
Time & $07: 00$ & $08: 00$ & $09: 00$ & $10: 00$ & $11: 00$ & $12: 00$ \\
Charge percent & $1 \%$ & $0.5 \%$ & $0.5 \%$ & $1.5 \%$ & $2.5 \%$ & $2.5 \%$ \\
Time & $13: 00$ & $14: 00$ & $15: 00$ & $16: 00$ & $17: 00$ & $18: 00$ \\
Charge percent & $2.5 \%$ & $2.5 \%$ & $2.5 \%$ & $1 \%$ & $0.5 \%$ & $0.5 \%$ \\
Time & $19: 00$ & $20: 00$ & $21: 00$ & $22: 00$ & $23: 00$ & $24: 00$ \\
Charge percent & $2 \%$ & $4 \%$ & $6 \%$ & $9 \%$ & $10 \%$ & $10 \%$ \\
\hline
\end{tabular}


load is met mainly by gas and wind. Meanwhile, the gas generators will act as support generator when wind is low. The results of baseline model for 2025 are shown in Table 7.

\section{Resultsand Analysis}

The validated SEM model [13] was a fundamental starting point to carry out this analysis as a complete set of baseline transmission and generation data was already set-up in PLEXOS. As the EV load demand and charging behaviors are highly unpredictable, different scenarios of EV charging, a range for load demands and charging profiles were examined in the 2025 SEM model.

\subsection{Off-Peak Charging in Model}

Off-peak charging means to allocate all the charging power during off-peak load time periods. It can be clearly seen from Figure 1 and Table 6 that the off-peak EV charging scenario makes a huge load on the baseline system during the night from 00:00. The profiles of dispatch change due to the off-peak EV charging are illustrated in Figure 2. Obviously, it could be found from Figure 2 that gas is the predominant energy to meet the EV load. However, the additional demand from EV is also powered by other generators.

The profiles of off-peak load and base line load at 8th June 2025 were simulated using our model. It could be found that the maximum power appears during the day time (Figure 3). The annual cost to all EV and average price paid by purchaser are calculated as $£ 61,568$ and $£ 195$ respectively. EV renewable load of wind variability during off-peak is 503.87 GWh and EV Renewable Load is 1259.67 GWh. EV Renewable Load (kTOE) is 108.33 GWh. Thus the contribution to $10 \%$ renewable energy target (\%) of wind variability during off-peak is estimated to be $2.07 \%$. All outputs from the simulations in PLEXOS for each charging scenario, such as generation cost, system marginal price (SMP), emissions, cost of EV and so on, are reported in Tables 8-10, respectively.

\subsection{Annual Power System with EV Load}

Annual power system characteristics for each scenario are reported in Table 11. It is found that the ability of EVs to reduce GHGs emissions is highly relative to the multitudinous factors of generators in a generation portfolio, the type of the charging portfolio and the time of day when charging.

Table 7. Power system characteristics of 2025 SEM.

\begin{tabular}{cc}
\hline Total Generation Cost (£,000) & 1693576.61 \\
Load-Weighted Average SMP (£/MWh) & 55.56 \\
Wind Curtailment Factor (\%) & 0.26 \\
$\mathrm{CO}_{2}$ Emissions(kt) & 15,851 \\
$\mathrm{NO}_{\mathrm{x}}$ Emissions (kt) & 50.12 \\
$\mathrm{SO}_{\mathrm{x}}$ Emissions (kt) & 39.38 \\
\hline
\end{tabular}

Table 8. Power system characteristics of the 2025 sem with off-peak charging.

$\begin{array}{cc}\text { Charges in Total Generation Cost }(£) & 61568.29 \\ \text { Load-Weighted Average SMP (£/MWh) } & 55.91 \\ \text { Wind Curtailment Factor (\%) } & 1.5 \\ \text { Annual Cost to Load per EV (£) } & 195 \\ \text { Average Load-Weighted Price Paid by Purchase } \mathrm{r}(£) & 52.57\end{array}$

Table 9. Emissions generated in 2025 sem due to off-peak charging.

\begin{tabular}{cc}
\hline Changes in Emissions & PHEV \\
\hline $\mathrm{CO}_{2}$ Emissions (kt) & 510.69 \\
$\mathrm{NO}_{\mathrm{x}}$ Emissions (kt) & 1.69 \\
$\mathrm{SO}_{\mathrm{x}}$ Emissions (kt) & 0.76 \\
\hline
\end{tabular}


Table 10. Target contributions due to wind variability and off-peak.

\begin{tabular}{ccc}
\hline EV Renewable Load $(\mathrm{GWh})$ & EV Renewable Load-2.5 Weighting $(\mathrm{GWh})$ & EV Renewable Load (kTOE) \\
\hline 503.87 & 1259.67 & 108.33 \\
\hline $10 \%$ renewable energy target (\%) & Net Reduction in $\mathrm{CO}_{2}(\mathrm{kt})$ & $20 \%$ emissions target (\%) \\
\hline 2.07 & 229.3 & 1.74 \\
\hline
\end{tabular}

Table 11. Annual power system characteristics for each scenario.

\begin{tabular}{|c|c|c|c|c|c|c|c|c|c|c|}
\hline Model & $\begin{array}{l}\text { Demand } \\
\text { (GWh) }\end{array}$ & $\begin{array}{c}\text { Generation } \\
\text { (GWh) }\end{array}$ & $\begin{array}{l}\mathrm{CO}_{2} \\
\text { (kt) }\end{array}$ & $\begin{array}{c}\mathrm{NO}_{\mathrm{x}} \\
\text { (kt) }\end{array}$ & $\begin{array}{l}\mathrm{SO}_{\mathrm{x}} \\
\text { (kt) }\end{array}$ & $\begin{array}{c}\text { SMP } \\
\text { (£/MWh) }\end{array}$ & $\begin{array}{c}\text { Total } \\
\text { generation } \\
\text { costs }(£)\end{array}$ & $\begin{array}{c}10 \% \\
\text { renewable } \\
\text { target }(\%)\end{array}$ & $\begin{array}{c}\text { Net } \\
\text { reduction in } \\
\mathrm{CO}_{2} \text { (kt) }\end{array}$ & $\begin{array}{c}20 \% \\
\text { emissions } \\
\text { target (\%) }\end{array}$ \\
\hline Baseline & 57536.4 & 57536.4 & 15,851 & 50.12 & 39.38 & 55.56 & 1.693576 & - & - & - \\
\hline Off-peak & 58792.6 & 58790.3 & 510.69 & 1.69 & 0.76 & 55.91 & 1.755145 & 2.07 & 229.3 & 1.74 \\
\hline Peak & 58857.8 & 58855.3 & 512.21 & 1.63 & 0.46 & 69.6 & 1.765830 & 1.74 & 227.75 & 1.68 \\
\hline Stochastic & 58846.7 & 58846.8 & 516.26 & 1.65 & 0.45 & 59.02 & 1.759621 & 1.92 & 223.7 & 1.65 \\
\hline EPRI & 58843.8 & 58843.6 & 517.28 & 1.66 & 0.49 & 55.96 & 1.760463 & 2.04 & 222.68 & 1.74 \\
\hline
\end{tabular}

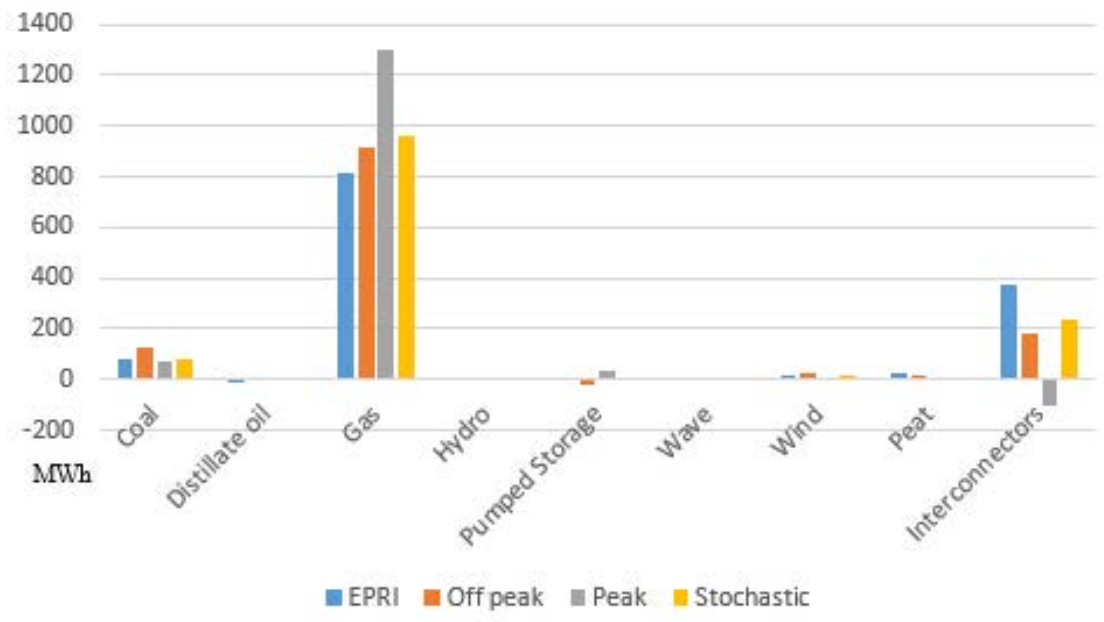

Figure 2. Dispatch changes due to EV charging.

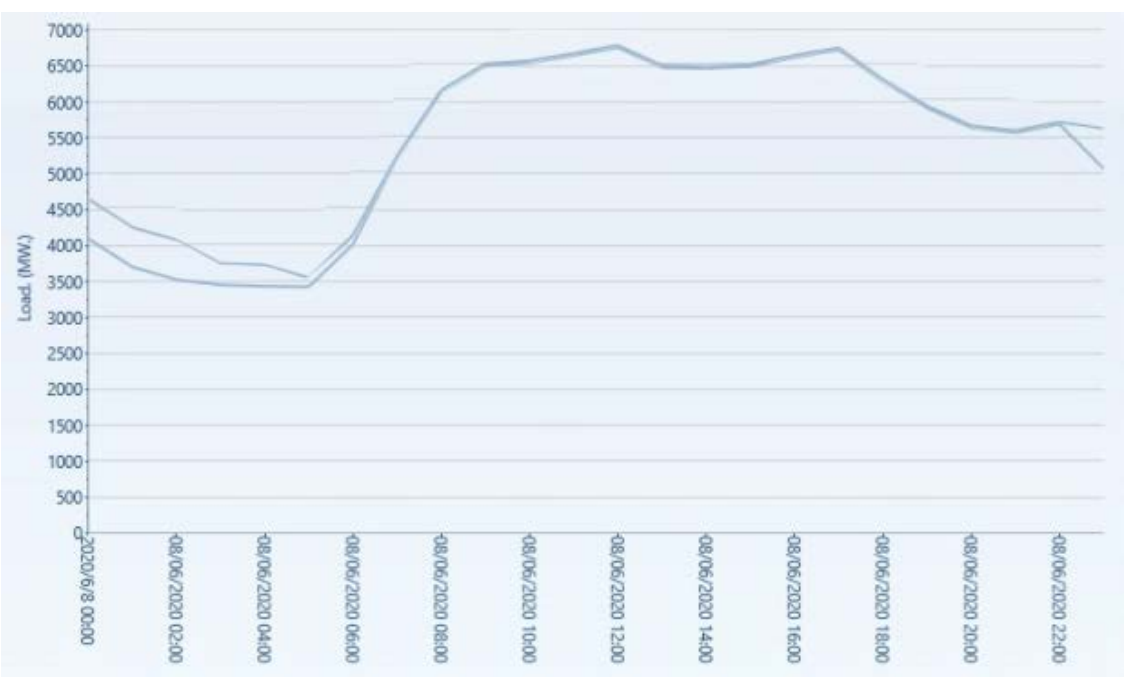

Figure 3. Profiles of off-peak load and base line load at 8th June 2025. 
The EV load was predominantly charged by gas dispatch in all the charging scenarios as showed in Figure 2. The gas was assisted by coal, wind, pumped hydro and interconnector power depending on the size of the EV load and the period of charging. In addition, the same demand in different charging time will cause the change of totally generation cost and emissions. The SMP is reduced from peak charging to off-peak or EPRI charging. This indicates that if the EV owners charge their EV during the night time will save more for both themselves and the SEM. The total generation and generation cost also will reduce by a proper time charging.

\section{Conclusion}

This paper has investigated the impacts of EV charging on the power system and SEM in a future case of 2025. The SEM model and the four EV charging profiles are built in PLEXOS. The results from these all models were analyzed to outline the effects of additional EV load combined in a future power system. The present investigation confirmed that the increasing penetration of EVs could contribute to approaching the target of the EU and Ireland government in terms of emission reduction, regardless of different charging scenarios. In addition, it could also be found that the off-peak charging is the best way to charge EV load by the comparison with other three types of charging as shown in the previous research, contributing $2.07 \%$ to the target of $10 \%$ reduction of Greenhouse gas emissions by 2025.

\section{Acknowledgements}

This work was financially supported by UK EPSRC under grant EP/L001063/1 and China NSFC under grants 51361130153 and 61273040 . The authors would also like to thank PLEXOS for providing software and Eirgrid SEMO and SONI for the datasets.

\section{References}

[1] International Energy Agency (IEA) (2008) World Energy Outlook. IEA and Organization for Economic Co-Operation and Development (OECD), Paris.

[2] Commission of the European Communities (2008) 2020 Europe’s Climate Change Opportunity. COM 30 Final.

[3] Hao, H., Wang, H. and Yi, R. (2010) Hybrid Modelling of China’s Vehicle Ownership and Projection through 2050. Energy, 36, 1351-1361. http://dx.doi.org/10.1016/j.energy.2010.10.055

[4] Zivin, J., Kotchen, M. and Mansur, E. (2014) Spatial and Temporal Heterogeneity of Marginal Emissions: Implications for Electric Cars and Other Electricity-Shifting Policies. Journal of Economic Behavior \& Organization, 107, 248-268. http://dx.doi.org/10.1016/j.jebo.2014.03.010

[5] Commission of the European Communities (2008) Communication from the Commission to the European Parliament, the Council, the European Economic and Social Committee and the Committee of the Regions.2020 by 2020 Europe's Climate Change Opportunity. COM (2008) 30 Final.

[6] Gormley, J. ()2008 Government Sets Binding Target for 40\% Power from Renewable Energy. Minister for Environment, Heritage and Local Government. [Press Release]

[7] European Parliament and Council of European Union. Decision No. 406/2009/EC, 2009.

[8] Foley, A., Gallachoir, B., Leahy, P. and McKeogh, E. (2009) Electric Vehicles and Energy Storage-A Case Study on Ireland. IEEE Vehicle Power and Propulsion Conference, Dearborn, 7-10 September 2009, 524-530. http://dx.doi.org/10.1109/VPPC.2009.5289805

[9] Doucette, R.T. and McCulloch, M.D. (2011) Modeling the Prospects of Plug-In Hybrid Electric Vehicles to Reduce $\mathrm{CO}_{2}$ Emissions. Applied Energy, 88, 2315-2323. http://dx.doi.org/10.1016/j.apenergy.2011.01.045

[10] Foley, A., Daly, H. and Gallachóir, B. (2010) Quantifying the Energy \& Carbon Emissions Implications of a 10\% Electric Vehicles Target. In: Proceedings of the 2010 International Energy Workshop.

[11] Foley, A., Winning, J. and Gallachoir, B. (2010) State-of-the-Art in Electric Vehicle Charging Infrastructure. IEEE Vehicle Power and Propulsion Conference (VPPC), Lille, 1-3 September 2010, 1-6.

[12] PLEXOS User Manual.

[13] Foley, A., Tyther, B., Calnan, P. and Gallachóir, B. (2013) Impacts of Electric Vehicle Charging under Electricity Market Operations. Applied Energy, 101, 93-102. http://dx.doi.org/10.1016/j.apenergy.2012.06.052

[14] Deane, J., Chiodi, A., Gargiulo, M., et al. (2012) Soft-Linking of a Power Systems Model to an Energy Systems Model. Energy, 42, 303-312. http://dx.doi.org/10.1016/j.energy.2012.03.052 
[15] Commission for Energy Regulation and Utility Regulator. Annual Load, Forecast, 2008.

[16] Medium and Long-Term Scenarios for Global Growth and Imbalances. http://www.oecd.org/berlin/50405107.pdf

[17] EirGrid and SONI Ltd. (2014) All-Island Generation Capacity Statement 2014-2023.

[18] DECC Fossil Fuel Price Projections.

https://www.gov.uk/government/uploads/system/uploads/attachment data/file/65698/6658-decc-fossil-fuel-price-proje ctions.pdf

[19] Electric Power Research Institute, Environmental Assessment of Plug-In Hybrid Electric Vehicles, Volume 2: United States Air Quality Analysis Based on AEO-2006 Assumptions for 2030, 2007, Palo Alto, CA and National Resources Defense Council, New York. 